\title{
Does low dose of etoricoxib play pre-emptive analgesic effect in third molar surgery? A randomized clinical trial
}

Long Xie ${ }^{1,2+}$, Lei Sang ${ }^{3+}$ and Zhi Li $i^{1,2^{*}}$

\begin{abstract}
Background: How to prevent pain after the extraction of impacted teeth is a serious challenge for all patients. The purpose of this clinical trial was to investigate whether pre-emptive low dose of etoricoxib can reduce postoperative pain in patients undergoing third molars surgery.

Methods: Patients were randomised to receive etoricoxib $60 \mathrm{mg}$ or placebo $30 \mathrm{~min}$ before surgery. Post-operative pain was recorded using a visual analogue scale during $24 \mathrm{~h}$ within the post-operative period. The total dose of ibuprofen rescue intake was recorded. Kaplan-Meier curves and log-rank analyses were used to evaluate the proportion of patients without rescue analgesic.
\end{abstract}

Results: Scores for the post-operative pain in the etoricoxib group were significantly lower than those in the placebo group during first $12 \mathrm{~h}(p<0.05)$. The number of patients without analgesic rescue medication was significantly lower in the etoricoxib group than in the placebo group. The average amount of rescue medication in the etoricoxib group $(0.4 \pm 0.9$ dose) was lower than that in the placebo group $(1.1 \pm 0.9$ doses, $p=0.004)$. Etoricoxib resulted in the longterm survival of patients without rescue analgesic $(p<0.001)$

Conclusions: This study revealed that etoricoxib has a substantial pre-emptive analgesic effect, resulting in the reduced use of analgesics after third molar removal.

Trial registration: Registered on ChiCTR1900024503. Date of Registration: 13/07/2019.

Keywords: Pre-emptive analgesia, Etoricoxib, Third molar, Extraction, Post-operative pain

\section{Background}

Acute pain caused by mandibular third molar removal is widely used to evaluate the efficacy of analgesics. Treatment of moderate or severe pain is usually given after the operation to reduce the dispersion of pain intensity measures by only including patients who need analgesics [1]. Agents, such as nonsteroidal anti-inflammatory

\footnotetext{
*Correspondence: zhili@whu.edu.cn

†Long Xie and Lei Sang contributed equally to this work and are considered as joint first authors

${ }^{2}$ Department of Oral and Maxillofacial Surgery, School and Hospital of Stomatology, Wuhan University, 237 Luoyu Road, Wuhan 430079, China Full list of author information is available at the end of the article
}

drugs (NSAIDs), acetaminophen and opioids, are effective in treating acute pain [2].

NSAIDs contain two cyclooxygenase isoforms, namely, cyclooxygenase- 1 (COX-1) and cyclooxygenase- 2 (COX2) [3]. COX-1 is constitutively expressed in tissues and promotes the synthesis of prostaglandin (PG). The gastric and renal side effects of NSAIDs may be due to their indirect influence on PGE2, which has a cytoprotective effect in the gastrointestinal system, as well as on PGE2 and PGI2, which regulate renal blood flow [4]. COX-2 is also located in certain healthy tissues, but this isoform is especially induced by inflammatory stimulus or mitogen in some tissues. The expression of COX-2 may be related

(c) The Author(s) 2021. Open Access This article is licensed under a Creative Commons Attribution 4.0 International License, which permits use, sharing, adaptation, distribution and reproduction in any medium or format, as long as you give appropriate credit to the original author(s) and the source, provide a link to the Creative Commons licence, and indicate if changes were made. The images or other third party material in this article are included in the article's Creative Commons licence unless indicated otherwise in a credit line to the material. If material is not included in the article's Creative Commons licence and your intended use is not permitted by statutory regulation or exceeds the permitted use, you will need to obtain permission directly from the copyright holder. To view a copy of this licence, visit http://creativecommons.org/licenses/by/4.0/. The Creative Commons Public Domain Dedication waiver (http://creativeco mmons.org/publicdomain/zero/1.0/) applies to the data made available in this article, unless otherwise stated in a credit line to the data. 
to the synthesis of PG, which induces responses to pathological processes, such as pain, fever and inflammation [5]. Although nonselective NSAIDs are first-line analgesics, their additional inhibition of COX-1 increases the hazard of gastrointestinal toxicity and thus limits their administration [6].

Etoricoxib, as the COX-2 selective class of NSAIDs, can provide patients with effective painkillers who do not benefit adequately from first-line therapies [7]. As the second generation of the selective class of NSAIDs, in various cells and whole blood tests, etoricoxib is more than 100 times selective for COX-2 than for COX-1 and is obviously less active against COX-1 than other selective COX-2 inhibitors [8]. This drug is also effective in relieving pain during dental procedures, total abdominal hysterectomy, periodontal surgery and therapeutic knee arthroscopy [9-12]. This type of NSAID is a safe and effective drug that controls postoperative pain with minimal side effects.

The pre-emptive analgesic of large doses of etoricoxib (120 mg) has been demonstrated to reduce pain after tooth extraction surgery [13]. At present, few studies were conducted on the use of low-dose etoricoxib $(60 \mathrm{mg})$ after the operation of impacted teeth, and the results cannot provide a basis for clinical practice [1]. Our clinical trial was performed to evaluate the efficacy of a low dose of etoricoxib $(60 \mathrm{mg})$ on alleviating pain after third molar surgery.

\section{Methods}

\section{Study design and sample}

This study was designed as a randomized, parallel, double-blinded and placebo-controlled clinical trial from August 2019 to July 2020. Healthy patients scheduled to undergo surgical removal of an impacted horizontal mandibular third molar (Winter classification) were eligible for participation. Patients were included if they were older than 18 years old, had horizontal impacted teeth, did not take analgesics or anti-inflammatory drugs a week prior to the study. Patients were excluded if they took NSAIDs and COX-2 inhibitors; were pregnant or nursing; had other serious diseases, such as liver, kidney and cardiovascular diseases; had ulcers or bleeding in the digestive tract; had the history of GI bleeding and gastritis; had inability to express subjective discomfort symptoms; and suffered from dental caries or apical periodontitis with the adjacent teeth. The Patients were given standardised participant information sheets and signed written informed consent for their participation.

All patients were informed about the study protocol and possible risks prior to any procedure. The patients were randomly divided into etoricoxib and placebo groups by Excel software. The etoricoxib group orally receive etoricoxib tablet $60 \mathrm{mg}$ (Merck\&Co., Inc) or placebo group (tablet, without active drug) $30 \mathrm{~min}$ before surgery. The operator and the patients were blinded to the type of drugs administered. To prevent postoperative infection, $0.5 \mathrm{~g}$ dose of amoxicillin and $0.4 \mathrm{~g}$ dose of metronidazole tablets were taken orally, 3 times a day, for 5 days, and $1.0 \mathrm{~g}$ dose of azithromycin was given once a day for 5 days if allergic to amoxicillin.

\section{Randomisation and blinding}

The patients were divided into two groups (placebo and $60 \mathrm{mg}$ of etoricoxib) by Excel software to achieve randomisation. Allocation concealment was maintained using a sealed opaque envelope. The research assistant prepared the study drugs for the clinic nurses according to the randomisation list. A dedicated nurse, as nontreatment group members, gave the study drugs sealed in a similar package to the patients $30 \mathrm{~min}$ before the surgery.

\section{Sample size calculation}

Based on the mean pain scores of previous study [14] (etoricoxib $1.9 \pm 1.5$ and placebo $3.6 \pm 1.9$ ), a minimum sample size of twenty-eight patients per group were required to conduct this clinical trial and statistically reject the null hypothesis with $95 \%$ power. For this sample calculation, the type 1 error associated with the test was $0.05 ; \mathrm{x}^{2}$ test without correction was used to evaluate the null hypothesis. The sample unit used in the present study was the third molar.

\section{Interventions}

All operations were performed by the same attending doctor to minimise differences between operators. The same local anaesthesia technique was performed on the patients. The anaesthesia of inferior alveolar, lingual and buccal nerves block was performed with $2 \%$ lidocaine. For local infiltration anaesthesia, $4 \%$ atecaine and 1:100,000 epinephrine (Septanest, Septodont, France) were used to reduce intraoperative bleeding. Both groups received the same surgical procedure to reduce surgery-related bias. The buccal mucoperiosteal flap was elevated, the bone was removed and the tooth was sectioned. After the tooth was extracted, the alveolar tissue was scraped and rinsed with sterile saline solution. The wound was sutured with a 4-0 silk, and the suture was removed 1 week after the surgery. The operative time was calculated from flap dissection and suture after tooth extraction. 


\section{Pain assessment}

An 11-point (0 to 10) visual analogue score (VAS) was used to evaluate pain ( 0 , no pain; $1-3$, mild pain; $4-6$, moderate pain; 7-9, severe pain; and 10, miserable pain.

). Postoperative pain was assessed and scored at $2,4,6,8,12$ and $24 \mathrm{~h}$ after the operation. Ibuprofen (300 mg) was prescribed as the emergency analgesic only in the case of VAS $>3$. The patients were asked to record their total consumption of ibuprofen (amount of tablets) within the first $24 \mathrm{~h}$ (at 2, 4, 6, 8, 12 and 24 h) and the time of the first analgesic rescue medication after the procedure was completed.

\section{Statistical analysis}

Data were analysed with SPSS software (SPSS, Inc., USA). Independent t-test and Chi-square were used to determine significant difference between the two groups. The parametric outcomes were expressed as mean \pm standard deviation (SD). The survival curves were estimated by the Kaplan-Meier method, and log-rank test was applied to compare differences between curves. $p$ value less than 0.05 was considered statistically significant.

\section{Results}

\section{Sample characterisation}

Eighty patients were considered eligible (Fig. 1). Twentyfour individuals were excluded because they did not meet

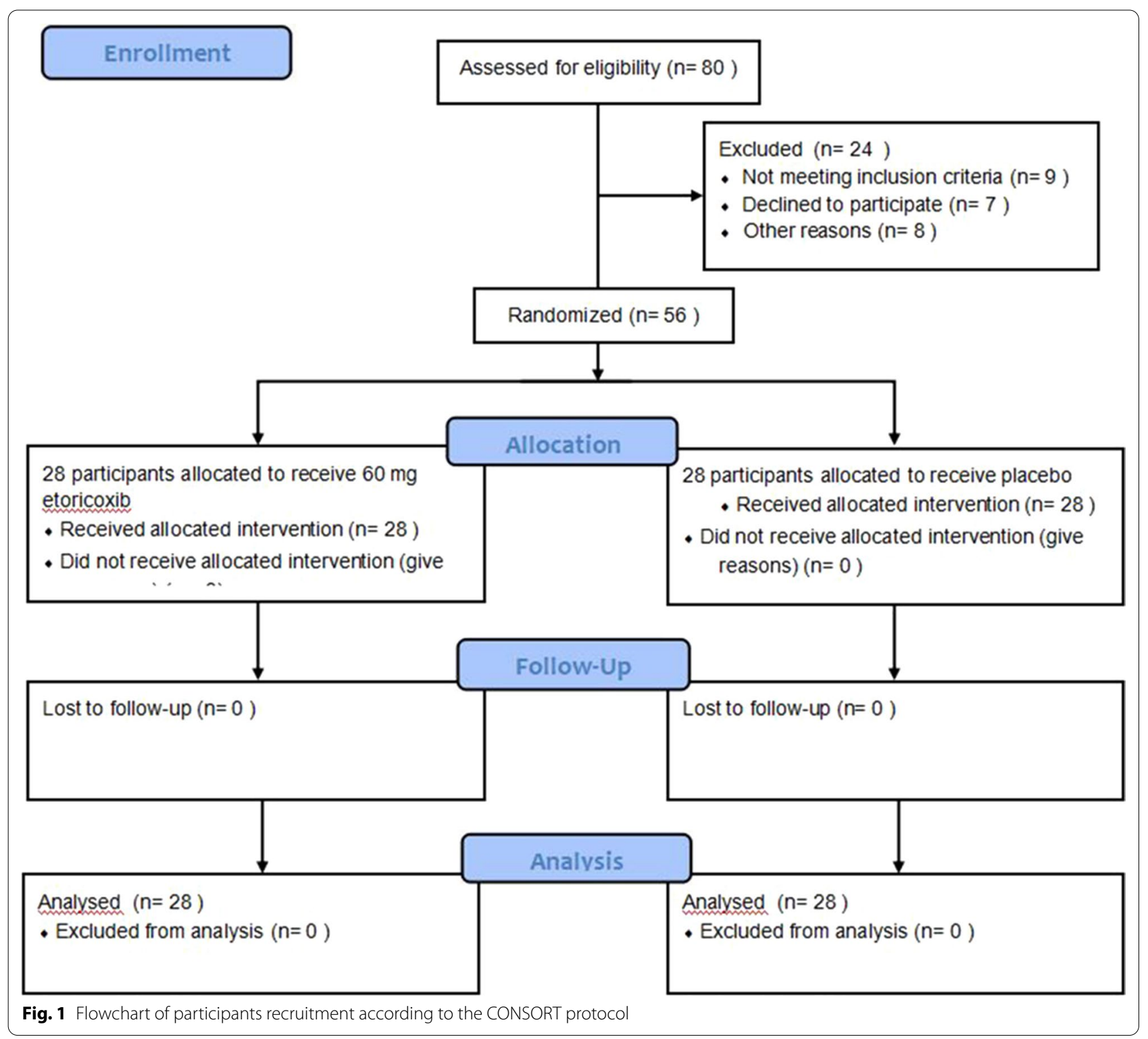


Table 1 Demographic data

\begin{tabular}{llll}
\hline & Placebo & Etoricoxib & $\boldsymbol{p}$ value \\
\hline Age(years) & $28.1 \pm 5.0$ & $29.4 \pm 5.0$ & $.368^{\mathrm{a}}$ \\
$\mathrm{BMl}\left(\mathrm{kg} / \mathrm{m}^{2}\right)$ & $21.4 \pm 3.0$ & $22.6 \pm 3.2$ & $.174^{\mathrm{a}}$ \\
Gender (M/F) & $10 / 18$ & $13 / 15$ & $.587^{\mathrm{b}}$ \\
Duration of the opera- & $14.0 \pm 4.8$ & $15.8 \pm 5.3$ & $.191^{\mathrm{a}}$ \\
tion (minutes) & & & \\
\hline
\end{tabular}

Data are presented as mean (standard deviation) or number

$\mathrm{BMI}$, body mass index

${ }^{a}$ By $t$ test

${ }^{\mathrm{b}}$ By $\mathrm{X}^{2}$ test

Table 2 Pell and Gregory classification

\begin{tabular}{lllll}
\hline & 2B & 2C & $\mathbf{X}^{\mathbf{2}}$ & $\boldsymbol{p}$ value \\
\hline Placebo $(n=29)$ & 18 & 11 & 0.284 & 0.790 \\
Etoricoxib $(n=29)$ & 16 & 13 & & \\
\hline
\end{tabular}

Table 3 Average pain measurements in study groups

\begin{tabular}{llll}
\hline $\begin{array}{l}\text { Timing of VAS } \\
\text { Score, } \mathbf{h}\end{array}$ & Placebo & Etoricoxib & $\boldsymbol{P}$ value \\
\hline 2 & $2.9 \pm 2.8$ & $1.1 \pm 1.4$ & $.004^{* *}$ \\
4 & $4.5 \pm 2.5$ & $2.1 \pm 1.6$ & $p<.001^{* * *}$ \\
6 & $3.8 \pm 2.3$ & $1.8 \pm 1.4$ & $p<.001^{* * *}$ \\
8 & $3.1 \pm 2.5$ & $1.5 \pm 1.5$ & $.006^{* *}$ \\
12 & $2.3 \pm 2.2$ & $1.1 \pm 1.5$ & $.027^{*}$ \\
24 & $1.5 \pm 1.5$ & $0.9 \pm 1.3$ & .112 \\
\hline
\end{tabular}

Values are expressed mean \pm standard deviation

VAS, visual analog pain scale

Values are expressed mean \pm standard deviation or number

${ }^{*} p<0.05$ t-test between groups

${ }^{* *} p<0.01$ t-test between groups

${ }^{* * *} p<0.001$ t-test between groups

the study criteria. Finally, 56 patients (male and female aged between 18 and 45 years) were selected for the clinical trial and randomly divided into etoricoxib and control groups. None of the drugs used had reported side effects. No differences were detected in terms of age, gender, BMI and duration of the operation between the two groups (Table 1). Table 2 shows the level of impaction (Pell-Gregory classification) for the patients in each of the study groups. There was no significant difference between the two groups for any parameter.

\section{Pain (VAS) analysis}

Table 3 and Fig. 2 show the mean VAS pain score at each postoperative time. The mean VAS score in the etoricoxib

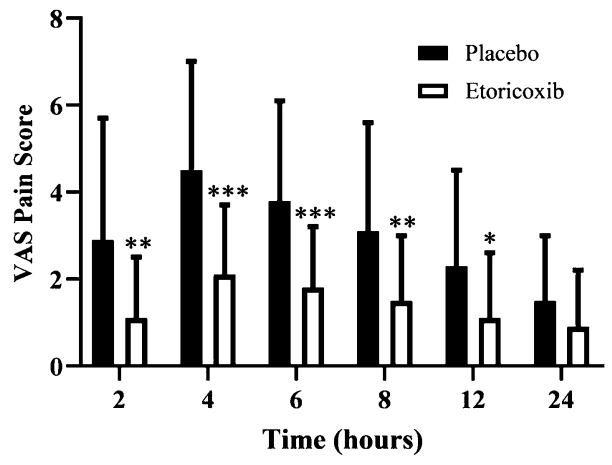

Fig. 2 Pain scores at 2, 4, 6, 8, 12 and $24 \mathrm{~h}$ after surgery as measured on visual analog scale (VAS)

group was significantly lower than that in the placebo group in the first $12 \mathrm{~h}$ during the follow-up period after the surgery.

\section{Rescue analgesic intake dose}

Table 4 shows the average consumption of rescue analgesic during the $24 \mathrm{~h}$ period. Patients in the etoricoxib group required less rescue analgesic compared with those in the placebo group.

\section{Interval to the first intake of ibuprofen}

The Kaplan-Meier curve in Fig. 3 shows the data of patients who took emergency analgesics within $24 \mathrm{~h}$ after the surgery. In the etoricoxib group, $71.4 \%$ of the patients did not take any painkillers after the surgery, which was $46.4 \%$ more than that in the placebo group $(P=0.001)$. The overall survival time (the interval to the first intake of ibuprofen) in the etoricoxib group was longer than that in the placebo group $(P<0.001)$.

\section{Discussion}

This study revealed that pre-emptive oral administration of etoricoxib $(60 \mathrm{mg})$ is an effective pain management strategy compared to placebo after third molar surgery. Etoricoxib $(60 \mathrm{mg})$ significantly reduced the pain scores during the first 12 postoperative hours, resulting in longer overall survival time (the interval to the first intake of ibuprofen) and reduced need of rescued analgesic consumption within $24 \mathrm{~h}$ after the surgery.

About $60 \%$ of the patients suffered moderate pain, and $40 \%$ had severe pain, which had higher requirements for analgesia [15]. Inadequate postoperative pain management resulted in a significant deterioration in the quality of life of the patients after third molar removal [16]. Therefore, pain management after third molar removal has received extensive attention from surgeons and patients. In 2010, the Italian Society of 
Table 4 Comparison of the average dosage and number of patients during 24-h rescue analgesic intake among groups

\begin{tabular}{|c|c|c|c|}
\hline Variable & $\begin{array}{l}\text { Placebo } \\
(\mathrm{n}=28)\end{array}$ & $\begin{array}{l}\text { Etoricoxib } \\
(\mathrm{n}=28)\end{array}$ & $p$ value \\
\hline $\begin{array}{l}\text { Number of patients who consumed the first rescue analgesic medication during the } \\
\text { period of evaluation }(24 \mathrm{~h})\end{array}$ & $21(75 \%)$ & $8(28.6 \%)$ & $.001^{\mathrm{b}}$ \\
\hline $\begin{array}{l}\text { Number (\%) of patients requiring no rescue analgesic medication during the period of } \\
\text { evaluation ( } 24 \mathrm{~h} \text { ) }\end{array}$ & $7(25 \%)$ & $20(71.4 \%)$ & $.001^{\mathrm{b}}$ \\
\hline Total analgesic consumption for postoperative $24 \mathrm{~h}$ (tablets) (mean \pm SD) & $1.1 \pm 0.9$ & $0.4 \pm 0.9$ & $.004^{\mathrm{a}}$ \\
\hline
\end{tabular}

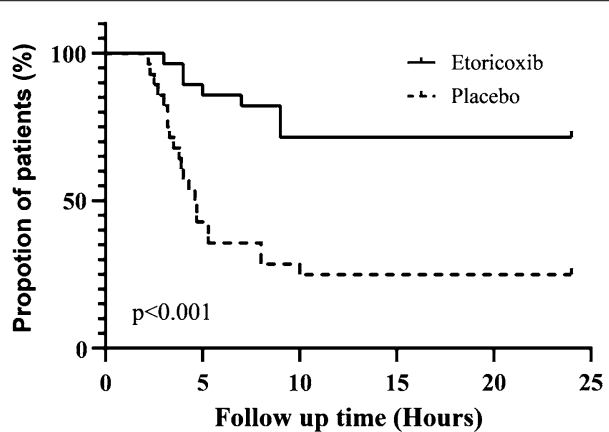

Fig. 3 Kaplan-Meier curve for overall survival stratified by etoricoxib group and placebo group use (Log rank test)

Odontostomatological Surgery made the recommendation that pre-emptive analgesia is expected to be the most effective method for controlling postoperative pain [17].

Pre-emptive analgesia is a treatment initiated before the operation to prevent central sensitisation due to incision injury and other inflammatory reactions [18]. Preemptive analgesia has been demonstrated to be safe and can decrease pain in the early postoperative period [19]. This method has achieved good analgesic effects in several kinds of surgical operations. Pre-emptive analgesia of etoricoxib can reduce acute postoperative pain in patients who underwent orthopaedics surgery, laparoscopic cholecystectomy and panphotocoagulation [20-22]. Albuquerque et al.[14]. found that pre-emptive analgesia of etoricoxib $(120 \mathrm{mg})$ can lead to reduce pain, trismus and oedema after third molar surgery.

A low dose of etoricoxib $(60 \mathrm{mg})$ showed significant analgesic effect and minimal side effects compared to placebo. In a previous study, 500 patients with osteoarthritis (OA) were administered with $60 \mathrm{mg}$ of etoricoxib once a day for 4 weeks without prior medication washout. Disability and pain interference in daily activities were significantly improved [23]. In addition, the pain and disability scores measured by the Western Ontario and McMaster's University OA index (WOMAC) in 19 extremely elderly men with OA (mean age, 85.9 years; age range, 79-96 years) were lower after treatment with $60 \mathrm{mg}$ of etoricoxib once daily for 4 weeks; no adverse events were also reported [24]. A double-blind and placebo-controlled study conducted a two-part doseranging clinical trial of etoricoxib $(5-90 \mathrm{mg} /$ day) starting at 14-week; during which, $60 \mathrm{mg}$ of etoricoxib was found to have the best analgesic effect according to the WOMAC pain scale [25]. Another clinical trial during the 46-week active-comparator controlled period, drug-related laboratory adverse experience, such as increase in alanine aminotransferase and aspartate aminotransferase, were reported for $2.0 \%, 0.0 \%, 4.1 \%$ and $11.8 \%$ in the groups administered with 30,60 and $90 \mathrm{mg}$ of etoricoxib and $150 \mathrm{mg}$ of diclofenac, respectively [26]. These studies indicated that a low dose of etoricoxib $(60 \mathrm{mg})$ is safer than other doses.

In our study, a low dose of etoricoxib $(60 \mathrm{mg})$ was more effective than placebo in preventing pain at first $12 \mathrm{~h}$ post-surgery. Gupta et al. discovered that a low dose of etoricoxib $(60 \mathrm{mg})$ was highly effective in controlling pain during fixed orthodontic appliance therapy [27]. In an acute pain model, postoperative analgesia of low dose of etoricoxib $(60 \mathrm{mg})$ can reduce pain [1]. Our research is similar to the above-mentioned study. However, according to Costa et al., pre-emptive $120 \mathrm{mg}$ etoricoxib single dose provided significant analgesia compared to placebo in the first $48 \mathrm{~h}$ after surgery (compared to $12 \mathrm{~h}$ in present study), with no side effects [13]. Although pre-emptive treatment with $120 \mathrm{mg}$ etoricoxib had a longer-lasting analgesic effect compared to $60 \mathrm{mg}$ etoricoxib, patients in Costa and this study experienced mild pain $24 \mathrm{~h}$ after surgery. To reduce mild pain, increasing the dose of etoricoxib may increase the risk of adverse reactions [26]. Furthermore, in Costa's trial, the sample size was only 18 patients. If the sample size was increased, the odds of adverse reactions among patients might be increased. In this study, a pre-emptive of low dose of etoricoxib was enough to induce good analgesia with no side effects. 
It should be noted that at the most pain intensity, the mean VAS measurements of treatment and placebo groups were 2.1 and 4.5 in this study. Maximum pain in this study was moderate in the placebo group. This may be related to the experience and skill of the surgeon. It is also clearly aware that the analgesic effect of low dose of etoricoxib should be specified to the mild/moderate surgery and should not be generalized for all cases at present.

PGE2 was highly expressed in the peripheral tissue and central nervous system during and after the surgery; upregulated of PGE2 was associated with increased pain scores on the VAS scale [28]. Etoricoxib reached the cerebrospinal fluid (CSF) and the surgical site in an effective concentration and reduced the production of PGE2 at the presumed site of action [29]. This process resulted in complete blockade of PGE2 production in the surgical wound and CSF. This phenomenon can lead to pain relief and reduce demands for post-operative analgesics.

The total analgesic consumption at $24 \mathrm{~h}$ post-operation (tablets, mean $\pm \mathrm{SD})$ in the etoricoxib group $(0.4 \pm 0.9)$ was less than that $(1.1 \pm 0.9)$ in the placebo group. The statistical difference between the two groups could be attributed to the analgesia, namely, etoricoxib, applied in this study. Through clinical trials, Malmstrom et al. found that patients with moderate or severe pain after removal of two or more third molars who took $120 \mathrm{mg}$ of etoricoxib had reduced demand for rescue medication [30]. Steffens et al.[11]. proposed that the pre-emptive use of $120 \mathrm{mg}$ of etoricoxib can relieve the post-operative pain after open-flap debridement surgery and reduce the total amount of rescue medication needed. Lower TNF-a concentration can lead to less rescue medication as a result of pre-emptive administration of $120 \mathrm{mg}$ of etoricoxib after third molar removal compared with that in the placebo group [14]. In the present research, pre-emptive analgesia of low dose of etoricoxib $(60 \mathrm{mg})$ can reduce the need for emergency analgesics. This clinical trial showed longer interval between taking emergency analgesics in the etoricoxib group than in the placebo group. More patients in the control group (75.0\% patients) used emergency analgesics than in the etoricoxib group $(28.6 \%$ patients). Malmstrom and his colleagues discovered that during the $24 \mathrm{~h}$ of the study period, $52.0 \%$ of patients in the etoricoxib group $(60 \mathrm{mg})$ and $81.6 \%$ in the placebo group used rescue medication [1]. Compared with Malmstrom's study, the present study showed that less patients took emergency analgesics because of removal of one third molars and the pre-emptive administration of etoricoxib. The interval between the first use of emergency analgesics was $12.1 \mathrm{~h}$ (etoricoxib $60 \mathrm{mg}$ group) and $2.1 \mathrm{~h}$ (placebo group) [1]. These data are consistent with our finding that patients in the etoricoxib group had not a degree of pain who necessitate intervention by analgesics compared with those in the placebo group. The longterm analgesic effect could be related to the elimination half-life of etoricoxib in plasma for 25-30 h [31].

\section{Limitation}

This was a preliminary study with indispensable limitations. On the one hand, this study lacked a positive control group. This study found that low dose of etoricoxib was helpful to reduce postoperative pain after tooth extraction, but NSAID analgesics could also achieve this effect. Secondly, the postoperative follow-up time was only $24 \mathrm{~h}$, and the pain assessment after $24 \mathrm{~h}$ was not observed. In the future study, we will extend the followup time and focus on the effect of etoricoxib compared with other NSAID drugs on postoperative pain after tooth extraction.

\section{Conclusions}

This study revealed that a low dose of etoricoxib has preemptive analgesic effect, resulting in the reduced use of analgesics after third molar removal.

\section{Abbreviations \\ VAS: Visual analog scale; NSAIDs: Nonsteroidal anti-inflammatory drugs; COX-1: Cyclooxygenase-1; SD: Standard deviation; OA: Osteoarthritis; WOMAC: The Western Ontario and McMaster's University OA index; PG: Prostaglandin.}

\section{Supplementary Information}

The online version contains supplementary material available at https://doi. org/10.1186/s12903-021-01837-0.

Additional file 1. Trail protocol.

\section{Acknowledgements}

Not applicable.

\section{Authors' contributions}

LX and LS Contributed to the design of the study, data analysis, results interpretation and in writing the manuscript. ZL Participated in planning of the research, literature search and critically reviewing the manuscript. LX Participated in study design, clinical work, analyzing data, results interpretation and in writing the manuscript. ZL Contributed to planning the clinical study and critically reviewing and editing the manuscript. All authors read and approved the final manuscript.

Funding

This research received no external funding

Availability of data and materials

The datasets used and/or analysed during the current study are available from the corresponding author on reasonable request.

\section{Declarations}

Ethics approval and consent to participate

The study was conducted according to the guidelines of the Declaration of Helsinki, and approved by the Ethics Committee of School and Hospital of 
Stomatology, Wuhan University (approval number 2019-B11). Each parent signed an informed consent in the study.

\section{Consent for publication}

Not applicable.

\section{Competing interests}

The authors declare no conflict of interest.

\section{Author details}

${ }^{1}$ The State Key Laboratory Breeding Base of Basic Science of Stomatology (Hubei-MOST) and Key Laboratory of Oral Biomedicine Ministry of Education, School and Hospital of Stomatology, Wuhan University, Wuhan, China. ${ }^{2}$ Department of Oral and Maxillofacial Surgery, School and Hospital of Stomatology, Wuhan University, 237 Luoyu Road, Wuhan 430079, China. ${ }^{3}$ Department of Stomatology, Suzhou Vocational Health College, Suzhou, China.

Received: 22 July 2021 Accepted: 17 September 2021 Published online: 23 September 2021

\section{References}

1. Malmstrom K, Sapre A, Couglin H, Agrawal NG, Mazenko RS, Fricke JR Jr. Etoricoxib in acute pain associated with dental surgery: a randomized, double-blind, placebo- and active comparator-controlled dose-ranging study. Clin Ther. 2004;26:667-79.

2. Mehrabi M, Allen JM, Roser SM. Therapeutic agents in perioperative third molar surgical procedures. Oral Maxillofac Surg Clin North Am. 2007;19:69-84.

3. Seibert K, Zhang Y, Leahy K, Hauser S, Masferrer J, Isakson P. Distribution of COX-1 and COX-2 in normal and inflamed tissues. Adv Exp Med Biol. 1997:400A:167-70.

4. Süleyman H, Demircan B, Karagöz Y. Anti-inflammatory and side effects of cyclooxygenase inhibitors. Pharmacol Rep. 2007;59:247-58.

5. Meade EA, Smith WL, DeWitt DL. Differential inhibition of prostaglandin endoperoxide synthase (cyclooxygenase) isozymes by aspirin and other non-steroidal anti-inflammatory drugs. J Biol Chem. 1993;268:6610-4.

6. Wolfe MM, Lichtenstein DR, Singh G. Gastrointestinal toxicity of nonsteroidal antiinflammatory drugs. N Engl J Med. 1999;340:1888-99.

7. Brown JD, Daniels SE, Bandy DP, Ko AT, Gammaitoni A, Mehta A, Boice JA, Losada MC, Peloso PM. Evaluation of multiday analgesia with etoricoxib in a double-blind, randomized controlled trial using the postoperative thirdmolar extraction dental pain model. Clin J Pain. 2013;29:492-8.

8. Riendeau D, Percival MD, Brideau C, Charleson S, Dubé D, Ethier D, Falgueyret JP, Friesen RW, Gordon R, Greig G, Guay J, Mancini J, Ouellet M, Wong E, Xu L, Boyce S, Visco D, Girard Y, Prasit P, Zamboni R, Rodger IW, Gresser M, Ford-Hutchinson AW, Young RN, Chan CC. Etoricoxib (MK-0663): preclinical profile and comparison with otheragents that selectively inhibit cyclooxygenase-2. J Pharmacol Exp Ther. 2001;296:558-66.

9. Daniels SE, Bandy DP, Christensen SE, Boice J, Losada MC, Liu H, Mehta A, Peloso PM. Evaluation of the dose range of etoricoxib in an acute pain setting using the postoperative dental pain model. Clin J Pain. 2011;27:1-8.

10. Viscusi ER, Frenkl TL, Hartrick CT, Rawal N, Kehlet H, Papanicolaou D, Gammaitoni A, Ko AT, Morgan LM, Mehta A, Curtis SP, Peloso PM. Perioperative use of etoricoxib reduces pain and opioid side-effects aftertotal abdominal hysterectomy: a double-blind, randomized, placebo-controlled phase III study. Curr Med Res Opin. 2011;28:1323-35.

11. Steffens JP, Santos FA, Sartori R, Pilatti GL. Preemptive dexamethasone and etoricoxib for pain and discomfort prevention after periodontal surgery: a double-masked, crossover, controlled clinical trial. J Periodontol. 2010;81:1153-60.

12. Lierz P, Losch H, Felleiter P. Evaluation of a single preoperative dose of etoricoxib for postoperativepain relief in therapeutic knee arthroscopy: a randomized trial. Acta Orthop. 2012;83:642-7.

13. Costa FW, Soares EC, Esses DF, Silva PG, Bezerra TP, Scarparo HC, Ribeiro TR, Fonteles CS. A split-mouth, randomized, triple-blind, placebo-controlled study to analyze the pre-emptive effect of etoricoxib $120 \mathrm{mg}$ on inflammatory events following removal of unerupted mandibular third molars. Int J Oral Maxillofac Surg. 2015;44:1166-74.

14. Albuquerque AFM, Fonteles CSR, do Val DR, Chaves HV, Bezerra MM, Pereira KMA, de Barros Silva PG, de Lima BB, Soares ECS, Ribeiro TR, Costa FWG.
Effect of pre-emptive analgesia on clinical parameters and tissue levels of TNF- $\alpha$ and IL-1 $\beta$ in third molar surgery: a triple-blind, randomized, placebocontrolled study. Int J Oral Maxillofac Surg. 2017;46:1615-25.

15. Averbuch $M$, Katzper M. Severity of baseline pain and degree of analgesia in the third molar post-extraction dental pain model. Anesth Analg. 2003;97:163-7.

16. Duarte-Rodrigues L, Miranda EFP, Souza TO, de Paiva HN, Falci SGM, Galvão EL. Third molar removal and its impact on quality of life: systematic review and meta-analysis. Qual Life Res. 2018;27:2477-89.

17. Annibali S, De Biase A, Pippi R, Sfasciotti GL, Italian Society of Odontostomatological Surgery. A consensus conference on management of the lower third molar Italian Society of Odontostomatological Surgery. Minerva Stomatol. 2011;60:509-27.

18. Kissin I. Preemptive analgesia. Anesthesiology. 2000;93:1138-43.

19. Van Backer JT, Jordan MR, Leahy DT, Moore JS, Callas P, DominickT, Cataldo PA. Preemptive analgesia decreases pain following anorectal surgery: a prospective, randomized, double-blinded. Placebo-controlled trial. Dis Colon Rectum. 2018;61:824-9.

20. Boonriong T, Tangtrakulwanich B, Glabglay P, Nimmaanrat S. Comparing etoricoxib and celecoxib for preemptive analgesia for acute postoperative pain in patients undergoing arthroscopic anterior cruciate ligament reconstruction: a randomized controlled trial. BMC Musculoskelet Disord. 2010;11:246.

21. Ko-lam W, Paiboonworachat S, Pongchairerks P, Junrungsee S, Sandhu T. Combination of etoricoxib and low-pressure pneumoperitoneum versus standard treatment for the management of pain after laparoscopic cholecystectomy: a randomized controlled trial. Surg Endosc. 2016;30:4800-8.

22. Nascimento VP, Primiano HP Jr, Maia OO Jr, Pelayes D, Takahashi WY. Analgesic effect of etoricoxib $\left(\right.$ Arcoxia $\left.^{\circledR}\right) 120$ mg during retinal laser photocoagulation. Eur J Ophthalmol. 2012;22:388-92.

23. Lin HY, Cheng TT, Wang JH, Lee CS, Chen MH, Lei V, Lac C, Gammaitoni AR, Smugar SS, Chen WJ. Etoricoxib improves pain, function and quality of life: results of a real-world effectiveness trial. Int J Rheum Dis. 2010;13:144-50.

24. Huang WN, Tso TK. Etoricoxib improves osteoarthritis pain relief, joint function, and quality of life in the extreme elderly. Bosn J Basic Med Sci. 2018;18:87-94.

25. Gottesdiener K, Schnitzer T, Fisher C, Bockow B, Markenson J, Ko A, DeTora L, Curtis S, Geissler L, Gertz BJ. Results of a randomized, dose-ranging trial of etoricoxib in patients with osteoarthritis. Rheumatology (Oxford). 2002;41:1052-61.

26. Curtis SP, Bockow B, Fisher C, Olaleye J, Compton A, Ko AT, Reicin AS. Etoricoxib in the treatment of osteoarthritis over 52-weeks: a double-blind, active-comparator controlled trial NCT00242489. BMC Musculoskelet Disord. 2005;6:58.

27. Gupta M, Kandula S, Laxmikanth SM, Vyavahare SS, Reddy SB, Ramachandra CS. Controlling pain during orthodontic fixed appliance therapy with nonsteroidal anti-inflammatory drugs (NSAID): a randomized, double-blinded, placebo-controlled study. J Orofac Orthop. 2014;75:471-6.

28. Buvanendran A, Kroin JS, Berger RA, Hallab NJ, Saha C, Negrescu C, Moric M, Caicedo MS, Tuman KJ. Upregulation of prostaglandin E2 and interleukins in the central nervous system and peripheral tissue during and after surgery in humans. Anesthesiology. 2006;104:403-10.

29. Renner B, Zacher J, Buvanendran A, Walter G, Strauss J, Brune K. Absorption and distribution of etoricoxib in plasma, CSF, and wound tissue in patients following hip surgery - a pilot study. Naunyn Schmiedebergs Arch Pharmacol. 2010;381:127-36.

30. Malmstrom K, Ang J, Fricke JR, Shingo S, Reicin A. The analgesic effect of etoricoxib relative to that of cetaminophen analgesics: a randomized, controlled single-dose study in acute dental impaction pain. Curr Med Res Opin. 2005;21:141-9.

31. Agrawal NG, Porras AG, Matthews CZ, Rose MJ, Woolf EJ, Musser BJ, Dynder AL, Mazina KE, Lasseter KC, Hunt TL, Schwartz JI, McCrea JB, Gottesdiener KM. Single- and multiple-dose pharmacokinetics of etoricoxib, a selective inhibitor of cyclooxygenase-2, in man. J Clin Pharmacol. 2003;43:268-76.

\section{Publisher's Note}

Springer Nature remains neutral with regard to jurisdictional claims in published maps and institutional affiliations. 